\title{
A enfermagem obstétrica e sua interface com o modelo obstétrico brasileiro
}

\section{Obstetric nursing and its interface with the brazilian obstetric model}

\author{
Rosangela da Conceição Sant'anna Amaral' • Valdecyr Herdy Alves ${ }^{2} \bullet$ Audrey Vidal Pereira ${ }^{3}$ \\ Diego Pereira Rodrigues ${ }^{4} \bullet$ Luana Asturiano da Silva $^{5}$ Giovanna Rosário Soanno Marchiori ${ }^{6}$
}

\begin{abstract}
RESUMO
Objetiva-se analisar a inserção das enfermeiras obstétricas no cenário assistencial de uma maternidade de ensino no Rio de Janeiro. Estudo descritivo, exploratório, de natureza qualitativa, realizado com 15 profissionais de saúde e gestores em uma maternidade de ensino no município de Petrópolis, Estado do Rio de Janeiro, no período de dezembro de 2016 à março de 2017.A coleta de dados ocorreu por meio de entrevistas semiestruturada, e posteriormente foram transcritas e submetidas à análise de conteúdo na modalidade temática. Observou-se que a inserção das enfermeiras obstetras ocorreu pelo cumprimento de determinações da rede cegonha; para a transformação de um modelo biomédico para um humanizado na atenção ao parto e nascimento. Conclui-se que a estratégia da rede cegonha permitiu a inserção das enfermeiras, para se promover uma mudança de modelo, e trazer na sua prática a humanização do cuidado.
\end{abstract}

Palavras-chave: Serviços de saúde materno-infantil; Saúde da mulher; Parto; Parto humanizado; Enfermeiras obstétricas.

\begin{abstract}
The objective of this study was to analyze the insertion of obstetric nurses into the care setting of a teaching maternity hospital in Rio de Janeiro.A descriptive, exploratory study of a qualitative nature, carried out with 15 health professionals and managers in a teaching maternity hospital in the city of Petrópolis, State of Rio de Janeiro, from December 2016 to March 2017. Data collection was by semi-structured interviews, and were subsequently transcribed and submitted to content analysis in the thematic modality. It was observed that the insertion of the obstetrical nurses occurred by the fulfillment of determinations of the stork network; for the transformation of a biomedical model to a humanized one in the attention to childbirth and birth. It is concluded that the strategy of the stork network allowed the insertion of nurses, to promote a change of model, and to bring in their practice the humanization of care.
\end{abstract}

Keywords: Maternal-child health services;Women's health; Parturition; Humanizing delivrey; Nurse Midwives.

'Enfermeira. Mestre em Saúde Materno-Infantil. Faculdade Arthur Sá Earp Neto, Petrópolis, RJ - Brasil. E-mail: rosangelamaral I6@gmail.com

${ }^{2}$ Enfermeiro. Doutor em Enfermagem. Professor Titular da Escola de Enfermagem Aurora de Afonso Costa da Universidade Federal Fluminense. Rio de Janeiro - RJ, Brasil. E-mail: herdyalves@yahoo.com.br

${ }^{3}$ Enfermeiro. Doutor em Saúde Pública. Professor Adjunto da Escola de Enfermagem Aurora de Afonso Costa da Universidade Federal Fluminense. Rio de Janeiro - RJ, Brasil. E-mail: auviprof@yahoo.com.br

${ }^{4}$ Enfermeiro. Doutor em Enfermagem. Professor Adjunto do Centro Universitário Anhanguera de Niterói do Curso de Enfermagem. Rio de Janeiro - RJ, Brasil. E-mail: diego.pereira.rodrigues@gmail.com

${ }^{5}$ Enfermeira. Mestre em Enfermagem. Maternidade Municipal Dra.Alzira Reis. Rio de Janeiro - RJ, Brasil. E-mail: luanaasturiano@hotmail.com

${ }^{6}$ Enfermeira. Mestre em Saúde materno-infantil. Professora Adjunta da Faculdade Novo Milênio. Espírito Santo - ES, Brasil. E-mail: giovannasoanno@gmail.com Correspondência: Diego Pereira Rodrigues - Rua Desembargador Leopoldo Muylaert, 307, Piratininga - Niterói (RJ) - CEP: 24350-450. E-mail: diego.pereira. rodrigues@gmail.com 


\section{INTRODUÇÃO}

O modelo predominante e tradicional da assistência obstétrica no Brasil é direcionado ao médico obstetra e na atenção hospitalar,' tendo como o foco a soberania das condutas médicas empregadas ao aspecto patológico da gestação e parto, e culminando nas intervenções centradas no modelo tecnológico do parto. ${ }^{2}$

Esse modelo tem como ideário de considerar o corpo da mulher como máquina, e dentro dessa ideologia, traz o pensamento de ser manipulado e consertado, por um profissional capacitado, o médico, e por essa corrente de pensamento que o modelo tem o foco na intervenção do corpo da mulher. ${ }^{2}$

Com a mobilização de usuárias do serviço público, e profissionais de saúde começaram a questionar inúmeras práticas empregadas no contexto do parto e nascimento, em meados da década de 80 , como o excesso da medicalização, a episiotomia, e das altas taxas de cesarianas eletivas no país. Assim, o questionamento da perda da autonomia da mulher, que passou a ser submetida a procedimentos desnecessários, passando ao médico ganhar destaque e o principal protagonista do processo de nascimento, ${ }^{3}$ para uma mudança de modelo, e se começou a trazer o processo do modelo de humanização.

Desse modo, a inserção das boas práticas no parto normal, construído por base no modelo humanizado, em que foi instituída pela Organização Mundial de Saúde em 1985, tendo o inicio do processo de desconstrução do modelo tecnológico. ${ }^{4}$ Nesse sentido, essas condutas obstétricas promovidas pela Organização Mundial de Saúde propôs uma assistência baseada em evidências científicas com base com a classificação de condutas obstétricas no parto normal, segundo os critérios de utilidade, eficácia e risco. Essas recomendações deram origem às categorias de práticas na assistência ao parto normal: categoria $A$ - práticas, demonstradamente, úteis e que devem ser encorajadas; categoria B - práticas claramente prejudiciais ou ineficazes e que devem ser eliminadas; categoria $C$ práticas em que não existem evidências para apoiar sua recomendação e devem ser utilizadas com cautela até que novas pesquisas esclareçam a questão; categoria $D$ práticas que são frequentemente utilizadas de modo inadequado.' Desse modo, mesmo com as recomendações as mulheres no Brasil ainda são expostas as intervenções desnecessárias. ${ }^{5}$

Desse modo, o Ministério da Saúde começou o incentivo e a incorporação da enfermeira obstétrica nas equipes hospitalares e aposta na sua contribuição para redução no uso das intervenções e das cesáreas desnecessárias, que caracterizam a assistência obstétrica no País.' Ressalta-se com a incorporação da enfermeira obstétrica em algumas maternidades públicas da cidade do Rio de Janeiro, a partir de 1998, foi a primeira inicia- tiva tomada por instâncias governamentais nessa direção.A organização da assistência no modelo humanizado constitui-se uma exceção, com participação desse profissional na assistência estimada em território nacional em 10,0\% a I5,0\%.' E, a Rede Cegonha, por meio da Portaria $\mathrm{n}^{\circ} \mathrm{I} .459$ de 24 de junho de $201 \mathrm{I}$ veio a impulsionar a sua inserção e formação de recursos humanos para atenção humanizada ao parto e nascimento.

Desse modo, tem uma necessidade de compreender o processo da inserção das enfermeiras obstétricas a partir da demanda dos profissionais de saúde e gestores e a sua interlocução com a estratégia da Rede Cegonha em conformidade com os princípios do Sistema Único de Saúde, a partir da coordenação da Saúde da Mulher, que dispõe a respeito da efetividade da humanização da assistência ao parto e nascimento, ${ }^{6}$ compreendendo por meio de investigações os aspectos multidimensionais que envolvem a experiência do parto e as práticas obstétricas nos seus aspectos físicos, emocionais e sociais.

Assim, o estudo tem como objetivo: Analisar a inserção das enfermeiras obstétricas no cenário assistencial de uma maternidade de ensino no Rio de Janeiro.

\section{MÉTODO}

Estudo descritivo, exploratório, de natureza qualitativa, realizado na maternidade do Hospital de Ensino Alcides Carneiro, situado no município de Petrópolis, estado do Rio de Janeiro, Brasil, no período de dezembro de 2016 à março de 2017 com 15 gestores e profissionais de saúde que participaram da inserção de enfermeiras obstétricas no hospital de ensino. $O$ critério de exclusão correspondeu aos profissionais de saúde e gestores que estivesse afastado das suas funções, e aqueles que não se encontram mais como colaborador da unidade hospitalar.

Foi realizada entrevista semiestruturada sobre a inserção das enfermeiras obstetras, que ocorreu em ambiente privado, assim garantindo a privacidade do participante.As entrevistas cessaram por meio do processo de saturação dos dados. Os depoimentos foram coletados por apareIho digital, transcritos na íntegra e submetidos à análise de conteúdo na modalidade temática. ${ }^{7}$ Para assegurar o sigilo e o anonimato do depoimento dos participantes, estes foram identificados como 'Entrevistado' e receberam um código alfanumérico sequencial (EI, E2,... EI5).

Foi utilizada a unidade de registro a partir da temática como estratégia de organização do conteúdo das entrevistas. Para tanto, selecionaram-se cores distintas, com a finalidade de identificar cada unidade e agrupá-las, possibilitando, assim, uma visão geral da temática. As seguintes unidades de registro foram originadas: $A$ contratualização da Rede Cegonha: política indutora de mudanças de modelo assistencial ao Parto e Nascimento;A indução de mudança no modelo assistencial a partir da estratégia Rede 
Cegonha;A Rede Cegonha como indutora da inserção de enfermeiras obstétricas no processo de trabalho do Hospital de Ensino. Essas unidades de registro fundamentaram a construção do núcleo temático: $A$ inserção da Enfermagem Obstétrica no cenário do Hospital de Ensino Alcides Carneiro, originando a unidade temática: Expressões de profissionais de saúde e gestores sobre a estratégia Rede Cegonha e a indução na mudança do modelo de assistência ao parto e nascimento. Desse modo, a categoria temática formada na analise, a saber:A rede cegonha como marco político de transição do modelo obstétrico e a interface com a enfermagem obstétrica.

A pesquisa foi aprovada pelo Comitê de Ética em Pesquisa do Hospital Universitário Antônio Pedro, da Universidade Federal Fluminense, sob protocolo n. ${ }^{\circ}$ I.839.020/2016, conforme dispõe a Resolução n. ${ }^{\circ}$ 466/201 2 do Conselho Nacional de Saúde. ${ }^{8}$ Para concretizar a participação, todos os participantes assinaram o Termo de Consentimento Livre Esclarecido.

\section{RESULTADOS}

\section{A rede cegonha como marco político de tran- sição do modelo obstétrico e a interface com a enfermagem obstétrica}

Para os participantes, a inserção das enfermeiras obstétricas na maternidade ocorreu para cumprimento de determinações do programa da Rede Cegonha como apontado nos depoimentos a seguir:

Vou dizer basicamente o que eu sei, foi devido a inserção da Rede Cegonha no município de Petrópolis, por isso a necessidade de contratação. (E2) A contratação ocorreu por uma exigência do projeto de implantação da Rede Cegonha, que tem uma exigência da contratação de enfermeiras obstétricas na classificação de risco, não seria só na classificação, por enquanto nós só temos na classificação, mas para você começar com o projeto primeiro passo é ter enfermeiras obstétricas dentro da maternidade. (E4)

A Secretaria na época informou que o mesmo estava habilitado para que nós recebêssemos recursos da Rede Cegonha, que depois passou a ser incorporado ao teto financeiro do município e aí a necessidade de contratação das enfermeiras obstétricas foi para cumprir esses itens de tornar o hospital no caso vinculado à essa questão Rede Cegonha, dessas enfermeiras com especialização em obstetrícia, foi para atender na verdade à parametrização do Ministério. (E9)

Os participantes apontaram para a importância da enfermagem obstétrica na transformação no modelo de atenção ao parto e nascimento:

O nosso objetivo não é só atender a rede cegonha, a gente queria inserir um profissional na maternidade que começasse a dar a maternidade aquela cara de serviço humanizado, de acolhimento, de tratar a gestante não como doente, mas como aquela chega para ganhar um presente, ganhar um filho é um presente, é o maior presente, com certeza. (EI)

O Objetivo principal é que entre os pilares da Rede Cegonha é exigido que tenha enfermeiras obstétricas, porquê? Porque essa enfermeira obstétrica vai ter um olhar holístico, para trabalhar mãe, bebê, puérpera de uma forma mais humaniza$\mathrm{da}$, mais contato e tudo que envolve os pilares da Rede Cegonha que aí já é muita coisa que envolve, não é só o parto é o enfermeiras obstétricas atuando em todos os "cantinhos. (E7)

Sem dúvida um melhor atendimento para as gestantes e parturientes, melhor condição de saúde, acolhimento, o direito de se conhecer enquanto mãe, de conhecer o parto, entender o processo que ninguém explica, quem explica é a enfermagem sem dúvida, alguém para ficar com elas ali para dar o suporte, e alguém preparado tecnicamente para fazer um parto de primeira linha. (EI5)

A implantação de um modelo humanizado, e a possibilidade para uma mudança do modelo hegemônico na atenção ao parto e nascimento, com as inserção da enfermagem obstétrica se mostra necessário, por meio da Rede Cegonha, que segundo os participantes tem obstáculos para a sua execução na totalidade nas condutas da enfermagem obstétrica, conforme os depoimentos:

A gente partiu primeiro para classificação de risco. A proposta inicial foi preencher as vagas na classificação de risco, para depois num segundo momento partir para enfermeira obstetra atuando na assistência. Aqui trabalhamos há muitos anos sem a inserção do enfermeiro, nós achamos mais prudente ir por etapas. Primeiro adaptar todos os profissionais médicos com a triagem obstétrica, nas práticas da classificação de risco, para em um segundo momento colocar então um enfermeiro assistencialista. (EI)

Sei que a enfermeiras obstétricas tem não só que fazer admissão, mas também acompanhar a todo um processo e ela fazer o parto, e nós não temos isso aqui, elas estão só na admissão fazendo a triagem e a gente tem que avançar muito nisso. Sim avançar, porque elas estão só fazendo a triagem a gente tem que caminhar para o parto e conseguir fazer o parto, eu confesso que é essa a minha opinião particular, porque o enfermeiro no (ocorre neste momento uma diminuição no tom da conversa, passa a falar mais baixo e diz que vai falar 
porque sabe ser sigiloso) consegue fazer o parto mais humanizado. (E2)

Nesse momento a gente começou pela classificação de risco, então a entrada delas foi pela implementação da Rede Cegonha. Na época nós contratamos 4 enfermeiras obstétricas para trabalhar em escala de plantão $24 \times 72 \mathrm{~h}$ e ficam aqui na admissão e observação que faz parte deste bloco. (E9)

Outro aspecto a ser destacado, refere-se ao aspecto da hegemonia médica, pois ao serem indagados sobre o processo de trabalho das enfermeiras obstétricas, os participantes revelaram questões que demonstraram que a classe médica, carregada de práticas medicalizadas, torna-se o principal impeditivo para o desempenho das condutas obstétricas realizadas pelas enfermeiras, conforme depoimentos à seguir:

Literalmente, humanizar o atendimento da enfermagem, tirar o foco daquele trabalho que o médico tem o papel de curar, que não é esse o papel dele dentro da maternidade, mas como a nossa maternidade está inserida dentro de um hospital geral esta visão fica extremamente contaminada. (EI)

Por ser um hospital voltado muito para o serviço médico, inicialmente nós decidimos colocar os enfermeiros como classificador de risco obstétrico e fazendo acolhimento, e não colocar o enfermeiras obstétricas direto na sala de parto, foi como estivéssemos fazendo uma adaptação no serviço, mesmo assim, a gente enfrentou alguns problemas, porque inicialmente os enfermeiros eram chamados de apoio ou apoiadores, então a fala deles era: agora nós temos uns apoios, então vai ajudar um pouco o nosso trabalho. (E9)

Eu vejo hoje que a maior dificuldade é com a medicina mesmo, porque a gente tem plantonistas muito antigos, que fazem práticas que não contemplam a Rede Cegonha e isso é uma barreira, e até complicado falar disso, porque as normas que a Rede Cegonha preconiza é que o parto seja natural, se o parto é natural ele não pode ter indução com medicação, que é o que a gente vê rotineiramente, porque a fala é a seguinte, vamos colocar para nascer, então vamos colocar para nascer significa acelerar esse processo fisiológico. E outra coisa também é a submissão do paciente pelo profissional. (EIO)

Em contrapartida, compreende-se que mudar um modelo predominante impregnado na formação na área da saúde não é uma tarefa fácil de realizar, principalmente se não houver um diálogo entre as partes envolvidas. Em alguns depoimentos, destaca-se a maneira como esses profissionais de saúde foram inseridas no serviço, tendo um impacto negativo na aceitação de parte integrante da equipe obstétrica, como nos depoimentos a seguir:

Elas foram contratadas e aí a gente fez uma ambiência com elas por todo o hospital, elas passaram pela Neo, alojamento conjunto, apresentadas aos técnicos e à admissão, a gente apresentou ao corpo de enfermagem e ao chefe médico, da equipe médica da obstetrícia e no decorrer dos plantões delas elas eram apresentadas as demais equipes. A gente nunca teve uma reunião de equipe de enfermagem, enfermagem obstétrica, técnicos de enfermagem, médicos. Isso a gente não teve, esse feedback. Logo quem nós chegamos, ninguém chegou e apresentou. Olha esse é o chefe médico responsável pela obstetrícia, essa é a equipe de enfermagem obstétrica que vai compor a equipe. Isso não houve, tanto que a gente teve alguns problemas de relacionamento e entendimentos, porque esse feedback, nós não tivemos. (E4)

A equipe médica não estava preparada para receber essas enfermeiras obstétricas, e qualquer problema que acontecesse ia ser um escândalo, então o que eu queria fazer primeiro: uma ambientação, essa era minha inicial, desses enfermeiros fazendo classificação de risco e acolhimento dessas pacientes, que esses enfermeiros se integrassem na equipe de obstetras até que isso se formasse laços de confiança profissional. (E8)

O quadro não estava completo e ela precisava de alguém que tivesse experiência e eu lá já trabaIhava com o protocolo do MS, o mesmo protocolo que ela utilizava aqui e aí eu fui indicada e já vim com a carteira de trabalho, então assim, não foi bem um processo seletivo, foi uma entrevista: olha você vai trabalhar aqui, o salário é esse e o trabalho é a classificação de risco e ponto final. Não houve treinamento, a coordenadora me passou que não havia tempo para treinar, que era para usar o mesmo protocolo utilizado na maternidade do Rio. (EIO)

É inegável que no contexto atual ocorreram avanços em algumas regiões do país, como nas regiões metropolitanas, onde algumas maternidades foram privilegiadas com a implantação do modelo humanizado por meio do incentivos da Rede Cegonha, e conseguiram manter a qualidade nas ações e serviços de saúde:

Eu fiz uma visita técnica em 2014 ao "Sofia Feldman" em Belo Horizonte, Minas Gerais, como já existia essa expectativa da gente ser credenciado pelo Rede Cegonha, naquela época a gente foi para conhecer para ver o que a gente podia estar modificando, se organizando, se antecipando, para quando chegasse o Rede Cegonha. Eu vi, presenciei lá, 
um dia inteiro, que é totalmente diferente do que a gente tem aqui, a presença da família, a circulação das pessoas dentro da maternidade, apesar de que lá eu sei é só maternidade, mas dentro de um modelo totalmente humanizado. (E4)

Eu vislumbro boa atuação da enfermeira obstétrica dentro da maternidade, eu vivencio experiências em outros locais como por exemplo o Fernandes Figueiras, a gente fez há uns 5 anos atrás uma visita ao Sofia Feldman em Belo Horizonte e a gente vê que quando a equipe está integrada, todo mundo ganha, ganha o médico, ganha a enfermagem, ganha o pessoal técnico de apoio e principalmente ganha mais a personagem principal que é a mãe e o bebê. (E6)

Somos capazes e conseguimos mudar os lugares, por exemplo eu trabalhei desde que me formei em três lugares, na minha residência no Mariska Ribeiro que é uma maternidade municipal do Rio de Janeiro, que é Rede Cegonha, e Cegonha Carioca que fez umas modificações, no Fernando MagaIhães que é no RJ também, que também é Cegonha Carioca, então dois modelos humanizados e o terceiro aqui, lá temos a enfermeiras obstétricas dentro da cena, atuando no trabalho de parto, porque lá ela tem autonomia para isso. (EI0)

\section{DISCUSSÃO}

A determinação da Rede Cegonha na inserção das enfermeiras obstétricas para a atuação na saúde materno-infantil, está relacionada à necessidade de mudança no quadro de atenção materna no país, fornecendo a mulher um cuidado humanizado, holístico e integral, fazendo valer seus direitos quanto a sua autonomia e seus valores pessoais. Ressalta-se que a incorporação da enfermagem obstétrica no modelo de atenção obstétrica mostra uma assistência com menores taxas de intervenções com a mulher, como a episiotomia, ocitocina, cesariana; e uma maior satisfação das mulheres quanto ao cuidado ofertado. ${ }^{9}$

Para tanto, o Conselho Federal de Enfermagem (COFEN) com a Resolução $n^{\circ}$ 0477/20 I 5 que dispõe sobre a enfermagem obstétrica, determina que entre outras atividades privativas ao seu exercício profissional, está declarada que cabe ao enfermeiro obstétrico além das suas atribuições legais, a assistência ao parto sem distócia, respeitando a individualidade da parturiente e priorizando a utilização de tecnologias não invasivas de cuidados. ${ }^{10}$ Dessa forma, mostra que a atuação a saúde materna, o enfermeiro com especialidade em enfermagem obstétrica tem o respaldo legal para a sua atuação, nas suas distintas ações preconizadas na Rede Cegonha, mostrando a necessidade de ampliação do cuidado para a mulher por meio da inserção das enfermeiras obstetras.

Desse modo, com a Rede Cegonha, com a inserção da enfermeira obstetra, o Ministério de Saúde (MS) promove a capacitação e a qualificação dos profissionais de saúde, valorizando o enfermeiro para que este possa agir de forma a prestar um serviço humanizado e de qualidade às mulheres e as crianças, dando uma resposta por meio das evidências científicas. Essas ações do MS vêm intensificando a formação e a especialização de profissionais com este perfil para atuarem junto à estratégia da Rede Cegonha."

A análise dos depoimentos dos entrevistados evidenciou que a valorização do parto humanizado deve ser levada em consideração, por aumentar a autonomia e o poder de decisão da mulher numa relação menos autoritária. Nesse contexto da assistência ao parto normal, implica das enfermeiras obstétricas uma atitude mais solidária entre o profissional e a mulher para uma boa evolução no trabalho de parto.

A atenção humanizada ao parto refere-se à necessidade de um novo olhar, compreendendo-o como uma experiência verdadeiramente humana. Acolher, ouvir, orientar e criar vínculo são aspectos fundamentais no cuidado às mulheres. $O$ conceito de humanização envolve atitudes, práticas, condutas e conhecimentos pautados no desenvolvimento saudável dos processos de parto e nascimento, respeitando a individualidade e valorizando as mulheres.Adotou-se a perspectiva do conceito de humanização conforme propõe o Programa de Humanização do Pré-natal e Nascimento (PHPN), o qual foi constituído em 2000, com o intuito de qualificar a atenção pré-natal no que tange ao seu acesso e cobertura, mas também aprimorar a atenção aos processos parturitivo e puerperal. ${ }^{3}$

Ressalta-se, que o processo de humanização ocorre por uma imposição da Política governamental, a qual tem por objetivo a diminuição das taxas de cesarianas, menor índices de intervenções e medicalizações no parto, além da implantação de práticas como: ambiente aconchegante, massagens, deambulação, possibilidades de partos na posição vertical, manejo da dor, promover o contato pele a pele entre mãe e bebê imediatamente após o nascimento, estimular a amamentação na primeira hora de vida e cumprir os dez passos para a proteção, a promoção e o apoio ao aleitamento materno, além da presença do acompanhante da escolha da mulher. ${ }^{12}$ Promovendo uma ruptura do modelo, e as enfermeiras obstetras se inserem nesse contexto de mudança.

Porém, nos depoimentos dos participantes mostras os obstáculos para a execução de todas as atividades de práticas da enfermagem obstétrica, preconizadas pela Rede Cegonha, principalmente na questão de autonomia para parto e nascimento, pois elas (enfermeiras obstetras) ficam restrita na função de acolhimento e classificação de risco. 
Desse modo, afirma-se que as práticas prejudiciais ao parto ainda ocorrem com frequência com as mulheres, demonstrando o autoritarismo dos profissionais de saúde, muitas vezes utilizados como forma de opressão ao desconhecimento das mulheres quanto aos seus direitos sexuais e reprodutivos, não sendo respeitadas as suas opiniões e realizadas ações sem seu conhecimento e consentimento. ${ }^{12-13}$

Apesar de todas as regulamentações, a questão competência e responsabilidade da enfermagem obstétrica ainda vem sendo questionada. Se por um lado as normas de Medicina determinam a competência dos médicos, por outro, a enfermeira obstétrica também possui suas atribuições e competências para fazer o diagnóstico obstétrico, que é a constatação do trabalho de parto eutócico e o desvio para o parto distócico. ${ }^{14}$ Mostrando a sua capacidade para atuar junto ao parto e nascimento, e quando se cria obstáculos para exercer as suas competências, mostra principalmente quanto o sistema biomédico, tecnocrática está inserido nas relação na atenção materna, dificultando a autonomia e também na ruptura do modelo de saúde, como perda de mercado.

Nestes discursos, observamos que a hegemonia médica predominante no cenário brasileiro é um fator dificultador na mudança do processo da inserção do enfermeiro obstetra no modelo humanizado. Constata-se que o modelo hegemônico predominante prejudica a assistência junto a mulher, dentro do que se esperava ter como atendimento humanizado, vencendo as barreiras da medicalização do parto e da hegemonia médica.

Ressalta-se que a assistência obstétrica no modelo colaborativo significa a integração do médico e da enfermeira obstétrica, com atuação conjunta para a qualidade da assistência e para a satisfação da mulher ficando as evidências científicas para a garantia dos direitos das muIheres.' O Modelo Colaborativo se constitui de forma predominante na organização da assistência obstétrica em países industrializados, como a Inglaterra, Alemanha, Países Escandinavos, Nova Zelândia, Canadá e Austrália, em que valoriza o processo fisiológico da mulher, e a redução das intervenções no parto, como a inserção da enfermeira obstetra no modelo de nascimento. ${ }^{15}$

Embora relações desiguais de poder marquem a interação médico/paciente em geral, neste caso, a nosso ver, a desigualdade pode ser transformada em atitudes de violência, cuja ocorrência está relacionada à conjugação de serem mulheres além de pacientes, anulando-as como sujeitos de direitos, particularmente os direitos sexuais e reprodutivos. Entendemos um lócus de exercício de poder instituído por meio de uma ideologia dominante com normas que determinam papéis sociais para homens e mulheres pautados na diferença sexual. ${ }^{16} \mathrm{Com}$ o médico na sua relação de cuidado, com inserção de intervenções obstétrica, anulando o direito de escolha da mulher, como a autonomia da enfermagem obstétrica, quando se estabelece como padrão o poder hegemônico na figura médica na obstetrícia.

Considera-se, a partir dos depoimentos, que ocorreram "falhas" na contratação das enfermeiras obstétricas, da forma de implantação, pois mudar um modelo de atenção não é processo simples, pois exige vários tipos de intervenções quanto a estrutura da unidade, de pensamento dos profissionais, de colaboração como equipe, de treinamento perante práticas utilizadas, e principalmente como política institucional, porém, a mudança deverá acontecer de forma verticalizada, ou seja, ela não poderá ser simplesmente imposta por uma estratégia do governo. Desse modo, ainda há muitos conflitos a serem superados entre os modelos de assistência e cuidados, e também na divisão dos espaços ocupados entre médicos e enfermeiros obstetras não condizentes com o Programa de Humanização ao Parto e Nascimento, juntamente com as diretrizes da estratégia da Rede Cegonha.

Considera-se que a mudança torna-se possível, desde seja um projeto político e institucional, e os participantes do estudo exemplificam em seus depoimentos que muitos hospitais conseguiram vencer os obstáculos e conseguiram implantar o modelo humanizado, com a perspectiva colaborativa entre os médicos e enfermeiros. Desse modo, é necessária a vontade política e a gestão eficiente, não podendo a Rede Cegonha ser vista como uma estratégia do governo que impõe mudanças, mas sim, como uma estratégia que visa ações que vão além do repasse financeiro e sim para a qualidade da assistência.

Essa estratégia provoca os gestores, profissionais de saúde e população em geral a compreenderem e debaterem suas questões no momento de sua implantação, para serem esclarecidas de forma prática e clara, dúvidas e incertezas, pois, só assim poderá ocorrer a transformação do modelo de atenção ao parto e nascimento praticado no país, o qual não coloca a gestante como protagonista do processo. ${ }^{17}$ Dessa forma, como ocorreu em locais como no município do Rio de Janeiro, na maternidade Leila Diniz, a maternidade Mariska Ribeiro; e em especial a maternidade Sofia Feldman, em Belo horizonte, em que modificaram um modelo hegemônico, com a inserção de um modelo humanizado para a garantia de um serviço colaborativo para a qualidade da assistência respaldado nas recomendações internacionais quanto a um parto saudável.

\section{CONCLUSÕES}

A Rede Cegonha aparece no cenário da saúde materna como uma importante estratégia política de saúde universal, que objetiva a implantação de um novo modelo de atenção ao parto e nascimento, com a garantia do acesso, melhor acolhimento e resolutividade, 
para diminuir as altas taxas de mortalidade e de cesarianas, para que possa implementar um modelo mais acolhedor e humanizado.

O estudo mostrou o processo de implantação das enfermeiras obstetras, em concordância com as recomendações da Rede Cegonha, preconizadas pelo Ministério da Saúde. $O$ processo sucedeu com ampla dificuldade da atuação ds enfermagem obstétrica, em que estava criando obstáculos, principalmente na legitimidade na atenção ao parto e nascimento, tendo com conduta de cuidado somente no acolhimento e classificação de risco, por um grande conflito vindo da equipe médica, pelo seu processo de inserção. Mas, a sua implantação se sucedeu com o objetivo principal de mudança de modelo na atenção a saúde da mulher, de uma atenção tecnocrática para humanizado.

Desse modo, mostra a necessidade de ampliação de um cuidado respaldado na humanização da assistência, rompendo os paradigmas da saúde, em relação ao modelo biomédico, medicalizado, e fornecendo alternativas para um cuidado mais acolhedor e humanizado, por meio de uma atenção compartilhada com enfermeiras e médico para uma atenção de qualidade. 


\section{REFERÊNCIAS}

I. Vogt SE, Silva KS, Dias MAB. Comparação de modelos de assistência ao parto em hospitais públicos. Rev Saúde Pública. 20 I4; 48(2): 304- I3.

2. David-Floyd R. The technocratic, humanistic, and holistic paradigms of childbirth. Int. J. Gynaecol Obstet. 200 I; 75(I): S5-S23.

3. Possati AB, Prates LA, Cremonese L, Scarton J, Alves CN, Ressel LB. Humanização do parto: significados e percepções de enfermeiras. Esc. Anna Nery. 20I7; 2 I (4): I-6.

4. Melo BM, Gomes LBS, Henriques ACPT, Lima SKM, Damasceno AKC. Implementação das boas práticas na atenção ao parto em maternidade de referência. Rev RENE. 2017; 18(3): 376-82.

5. Côrtes CT, Santos CS, Caroci AS, Oliveira SG, Oliveira SMJV, Riesco MLG. Metodologia de implementação de práticas baseadas em evidências científicas na assistência ao parto normal: estudo piloto. Rev esc enferm USP. 2015; 49(5): 716-25.

6. Ministério da Saúde (Br). Agenda nacional de prioridades de pesquisa em saúde. $2^{\mathrm{a}}$ ed., $3^{\mathrm{a}}$ reimpr. Brasília: Ministério da Saúde; 201 I.

7. Bardin L.Análise de conteúdo. $4^{\mathrm{a}}$ ed. Lisboa: Edições 70; $20 \mathrm{II}$.

8. Ministério da Saúde $(\mathrm{Br})$. Conselho Nacional de Saúde. Diretrizes e normas regulamentadoras de pesquisa envolvendo seres humanos. Resolução n. 466, de 12 de dezembro de 2012. Brasília: Ministério da Saúde; 2012.

9. Oliveira FAM, Leal GC,Wolff LDG, Rabelo M, Poliquesi CB.
Reflexões acerca da atuação do enfermeiro na Rede Cegonha. Rev enferm UFPE on line. 2016; 10:(Supl. 2): 867-74.

10. Conselho Federal de Enfermagem (Br). Resolução Cofen $n^{\circ} 0477$ de 14 de abril de 2015. Brasília: Conselho Federal de Enfermagem; 2015.

I I. Oliveira EM, Celento DD.A temática da Rede Cegonha e a inserção do enfermeiro nesse contexto. Revista de Saúde. 2016; 7(1):33-8.

12. Ministério da Saúde $(\mathrm{Br})$. Humanização do parto e do nascimento. Brasília: Ministério da Saúde; 2014.

13. Ferreira SL; Rocha MMS; Nunes IM.Atuação de enfermeiras obstetras no Sistema Único de Saúde (SUS-BA): estudo entre as egressas dos cursos de especialização em enfermagem obstétrica da EEUFBA. Rev Baiana Enferm. 2009;22-23 $(1,2,3): 22-32$.

14. Garcia SAL, Lippi UG, Garcia SAL. O parto assistido por enfermeira obstetra: perspectivas e controvérsias. RBPS. 2010; 23(4): 380-8.

I5. MalottAM, Davis BM, McDonald H, Hutton E. Midwifery care in eight industrialized countries: how does Canadian midwifery compare? J Obstet Gynaecol Can. 2009; 3 I (I0): 974-9.

16. Aguiar JM, D'Oliveira AFPL, Schraiber LB. Violência institucional, autoridade médica e poder nas maternidades sob a ótica dos profissionais de saúde. Cad. Saúde Pública. 2013; 29(I I): 2287-96.

17. Cavalcanti PCS, Junior GDG, Vasconcelos ALR, Guerrero AVP. Um modelo lógico da Rede Cegonha. Physis. 2013; 23(4): | 297-3 I6. 